\title{
Heating, Ventilation and Air Conditioning (HVAC) Systems
}

\author{
Md Sadiqul Hasan Talukder \\ B.Sc. in Mechanical Engineer, Department of Mechanical Engineering, Rajshahi University of Engineering \& \\ Technology, Bangladesh.
}

\begin{abstract}
This research work deals with the implication of modern retailing at not only in Dhaka, Bangladesh but also the whole district in Bangladesh with main objectives to find out technological activity, impact on modern welfare. HVAC is the most important side of Bangladesh. It is not only in Bangladesh but also the whole world.
\end{abstract}

Keywords: Manufacturing, Turbulent flow, Unidirectional airflow, Protection, Infiltration

\section{Introduction}

A quality pharmaceutical product depends on Heating, Ventilation and Air-conditioning (HVAC). Operator feels comfort when they obtain a well designed HVAC system. HVAC system design also influence architectural layouts with regard to items such as airlock positions, doorways and lobbies. Hence, Temperature, relative humidity and ventilation must be appropriate.

\section{Headings}

This guideline mainly focuses on recommendations for systems for manufacturers of oral solid dosage forms. Reference in this guideline is also made to other systems or components which are not relevant to solid dosage from manufacturing plants as these references may assist in providing a comparison between the requirements for different facilities.

\section{Indentations}

The definition given below apply to terms used in this guideline. They may have different meanings .

Acceptance_criteria

Measureable terms under which a test result will be considered acceptable.

\section{Action limit}

Action limit is reached when the acceptance criteria of a critical parameter have been exceeded. Results outside these limits will require specified action and investigation.

Air Handling Unit (AHU)

Air handling unit which serves to condition the air and provide the required air movement within a facility.

Airlock

An enclosed space with two or more doors, which is interposed between two or more rooms, e.g. of differing classes of cleanliness, for the purpose of controlling the airflow between those rooms when they need to be entered. An airlock is designed for and used by either people or goods (PAL=Personnel airlock and $\mathrm{MAL}=$ Material airlock).

\section{Alert limit}

Alert limit is reached when the normal operating range of a critical parameter has been exceeded, indicating that corrective measures may need to be taken to prevent the action limit being reached.

\section{API}

Active pharmaceutical ingredient

As-built

Condition where the installation is complete with all services connected and functioning but with no production equipment, materials, or personnel present.

\section{ASHRAE}

American Society of Heating, Refrigeration and Air Conditioning Engineers. 
At-rest

Condition where the installation is complete with equipment installed and operating in a manner agreed upon by the customer and supplier, but with no personnel present.

\section{Change control}

A formal system by which qualified representatives of appropriate disciplines review proposed or actual changes that might affect a validated status. The intent is to determine the need for action that would ensure that the system is maintained in a validated state.

\section{Clean area (clean room)}

An area (or room) with defined environmental control of particulate and microbial contamination, constructed and used in such a way as to reduce the introduction, generation and retention of contaminants within the area.

\section{Commissioning}

Commissioning is the documented process of verifying that the equipment and systems are installed according to specifications, placing the equipment into active service and verifying its proper action. Commissioning takes place at the conclusion of project construction but prior to validation.

\section{Containment}

A process or device to contain product, dust or contaminants in one zone, preventing it from escaping to another zone.

\section{Contamination}

The undesired introduction of impurities of a chemical or microbial nature, or of foreign matter, into or on to a starting material or intermediate, during production, sampling, packaging or repackaging, storage or transport.

\section{Critical parameter or component}

A processing parameter (such as temperature or humidity) that affects the quality of a product, or a component may have a direct impact on the quality of the product.

\section{Cross-contamination}

Contamination of a starting material, intermediate product or finished product with another starting material or material during production.

\section{Design condition}

Design condition relates to the specified range or accuracy of a controlled variable used by the designer as a basis to determine the performance requirements of an engineered system.

\section{Design qualification (DQ)}

DQ is the documented check of planning documents and technical specifications for design conformity with the process, manufacturing, GMP and regulatory requirements.

\section{Direct Impact System}

A system that is expected to have a direct impact on product quality. These systems are designed and commissioned in line with Good Engineering Practice (GEP) and, in addition, are subject to Qualification Practices.

\section{Facility}

The built environment within which the clean area installation and associated controlled environments operate together with their supporting infrastructure.

\section{Good Engineering Practice (GEP)}

Established engineering methods and standards that are applied throughout the project lifecycle to deliver appropriate, cost-effective solutions.

\section{HEPA filter}

High Efficiency Particulate Air filter. 


\section{Indirect impact system}

This is a system that is not expected to have a direct impact on product quality, but typically will support a direct impact system. These systems are designed and commissioned according to GEP only.

\section{Installation qualification (IQ)}

IQ is documented verification that the premises, HVAC system, supporting utilities and equipment have been built and installed in compliance with their approved design specification.

\section{Normal operating range}

Normal operating range is the range that the manufacturer selects as the acceptable values for a parameter during normal operations. This range must be within the operating range.

\section{Operating limits}

The minimum and/or maximum values that will ensure that product and safety requirements are met.

\section{Operating range} manufactured.

Operating range is the range of validated critical parameters within which acceptable products can be

\section{Operational condition}

This condition relates to carrying out room classification tests with the normal production process with equipment in operation, and the normal staff present in the room.

\section{Operational qualification $(\mathrm{OQ})$}

$\mathrm{OQ}$ is the documentary evidence to verify that the equipment operates in accordance with its design specifications in its normal operating range and performs as intended throughout all anticipated operating ranges.

OSD

Oral solid dosage - usually referring to an OSD plant that manufactures medicinal products such as tablets, capsules and powders to be taken orally.

\section{Performance qualification (PQ)}

$\mathrm{PQ}$ is the documented verification that the process and/or the total process related to the system performs as intended throughout all anticipated operating ranges.

\section{Pressure cascade}

A process whereby air flows from one area, which is maintained at the highest pressure to another area at a lower pressure.

\section{Qualification}

Qualification is the planning, carrying out and recording of tests on equipment and a system, which forms part of the validated process, to demonstrate that it will perform as intended.

\section{Relative humidity}

The ratio of the actual water vapour pressure of the air to the saturated water vapour pressure of the air at the same temperature expressed as a percentage. More simply put, it is the ratio of the mass of moisture in the air, relative to the mass at $100 \%$ moisture saturation, at a given temperature.

\section{Standard operating procedure (SOP)}

An authorized written procedure, giving instructions for performing operations, not necessarily specific to a given product or material, but of a more general nature, (e.g. equipment operation, maintenance and cleaning, validation, cleaning of premises and environmental control, sampling and inspection). Certain SOPs may be used to supplement product-specific master and batch production documentation.

\section{Turbulent flow}

Turbulent flow, or non-unidirectional airflow, is air distribution that is introduced into the controlled space and then mixes with room air by means of induction. 


\section{ULPA filter}

Ultra-Low Penetration Air filter (not applicable to normal pharmaceutical installations, but given for background information).

\section{Unidirectional airflow}

Unidirectional airflow is a rectified airflow over the entire cross-sectional area of a clean zone with a steady velocity and approximately parallel streamlines (see also turbulent flow). (Modern standards no longer refer to laminar flow, but have adopted the term unidirectional airflow.)

\section{Validation}

The documented act of proving that any procedure, process, equipment, material, activity or system actually leads to the expected results.

\section{Validation Master Plan (VMP)}

VMP is a high-level document which establishes an umbrella validation plan for the entire project, and is used as guidance by the project team for resource and technical planning (also referred to as master qualification plan).

\section{Scope}

HVAC systems needs design and GMP (Good Manufacturing Practices) requirements for oral solid dosage from facilities. Most of the system design principles for soild dosage manufacturing facilities will also apply to other facilities such as liquids, creams and ointments. This guideline does not cover requirements for manufacturing facilities for the production of sterile dosage products.

Manufacturers have their own engineering design and qualification standards and requirements may vary from one manufacturer to the next. Design parameters should, therefore be realistically set for each project, with a view to create a cost-effective design, complying with all regulatory standards and ensuring that product quality and safety are not compromised. The three primary aspects addressed in this manual are

the roles that the HVAC system plays in product protection, personnel protection and environmental protection. These aspects are represented in FIG:1

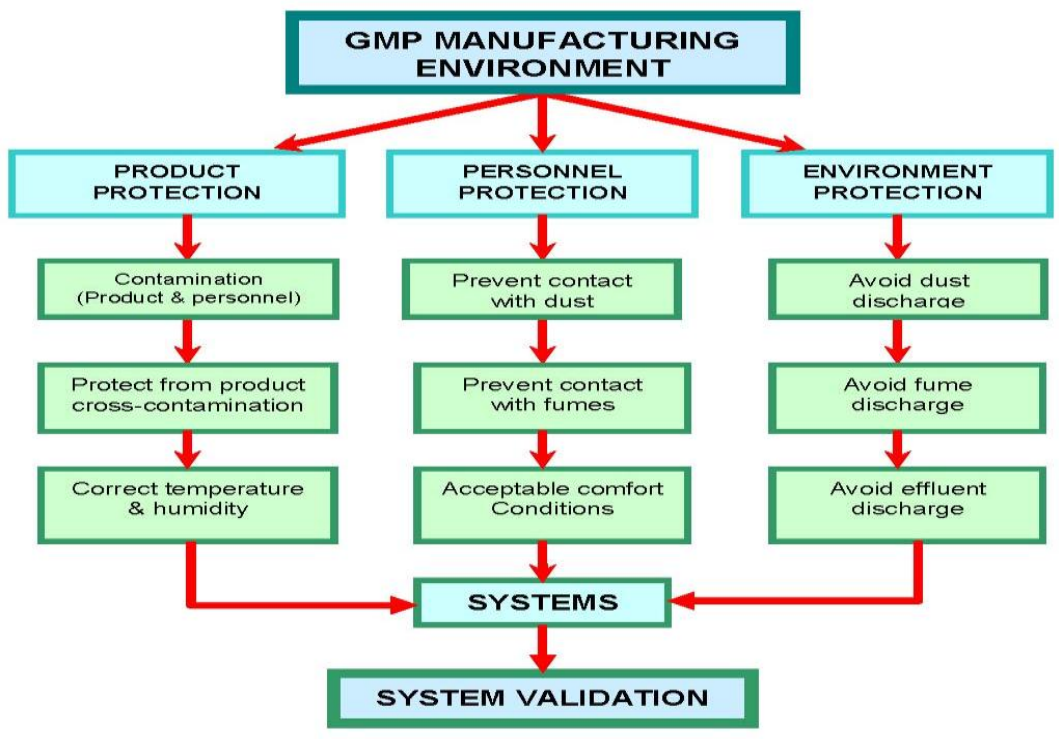

FIG: 1

\section{Protection}

Pharmaceutical manufacturing areas where pharmaceutical starting materials, intermediates, in-process materials and products, product contact utensils and equipment are exposed to the environment, should be classified as "clean areas".

The achievement of a particular clean area classification depends on a number of criteria which should be addressed at the design stage and qualification. There should be a balance between the different criteria in order to create an efficient clean area. 
Some of the basic criteria to be considered should include:

$>$ Building finishes and structure

$>$ Air filtration

$>$ Air change rate or flushing rate

$>$ Room pressure and pressure differentials

$>$ Location of air terminals and directional airflow

$>$ Temperature

$>$ Humidity

$>$ Material flow

$>$ Personnel flow

$>$ Equipment movement

$>$ Process being carried out

$>$ Outside air conditions

$>$ Occupancy

Air filtration and air change rates should ensure that the defined clean area classification is attained.

The air change rates should be determined by the manufacturer and designer, taking the various critical parameters into account. Primarily the air change rate should be set to a level that will achieve the required clean area classification.

Air change rates normally vary between 6 and 20 air changes per hour and are normally determined by the following considerations:

$>$ The quality and filtration of the supply air

$>$ Particulates generated by the manufacturing process

$>$ Particulates generated by the operators

Configuration of the room and air supply and extract locations

$>$ Sufficient air to achieve containment effect

$>$ Sufficient air to cope with the room heat load

$>$ Sufficient air to maintain the required room pressure

Each clean area class should be specified as achieving the clean area classification under "as-built", "at-rest" or "operational" conditions (FIG:2).

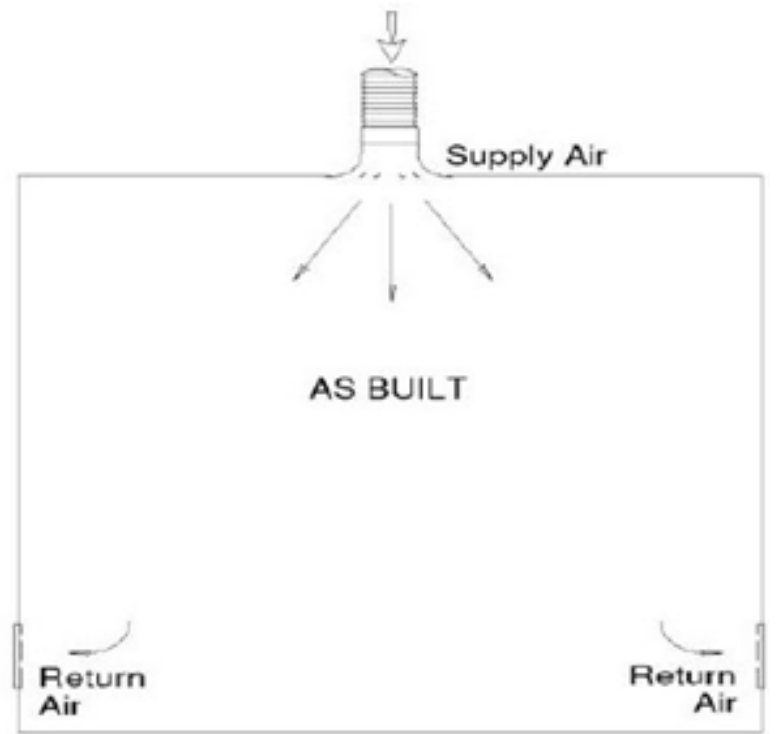

FIG: 2

\section{Air filtration}

The type of filters required for different applications, depends on the quality of the ambient air and the return air (where applicable) and also on the air change rates

Materials for components of an HVAC system should be selected with care so as not to become the source of contamination. Any component with the potential for liberating particulate or microbial contamination into the air stream should be located upstream of the final filters

Ventilation dampers, filters and other services should be designed and positioned so that they are 
accessible from outside the manufacturing areas (service voids or service corridors) for maintenance purposes (FIG: 3.1, 3.2, 3.3).

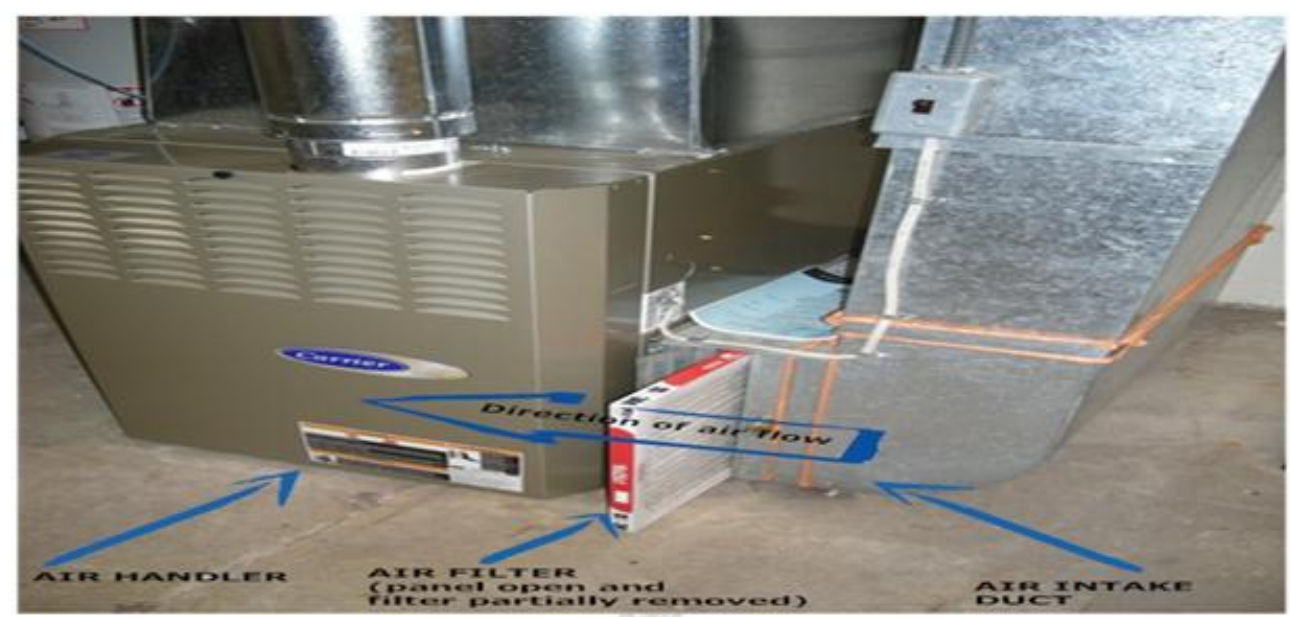

FIG: 3.1

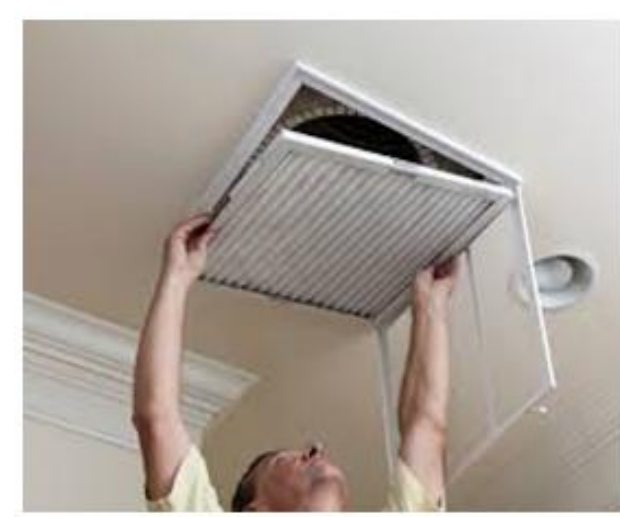

FIG: 3.2

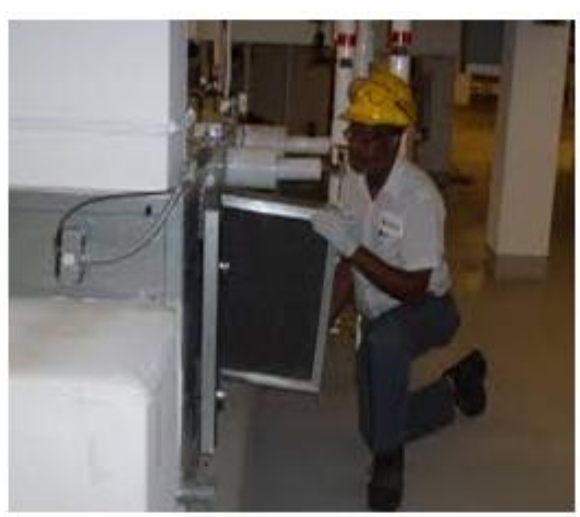

FIG: 3.3

Personnel should not be a source of contamination

Directional airflow within production or packing areas should assist in preventing possible contamination. Airflows should be planned in conjunction with operator locations, so as to minimize operator contamination of the product and also to protect the operator from dust inhalation.

HVAC air distribution components should be designed, installed and located to prevent contaminants generated within the room from being spread.

Supply air diffusers of the high induction type (e.g. those typically used for office-type airconditioning) should where possible, not be used in clean areas. Air diffusers should be of the non-induction type, introducing air with the least amount of induction so as to maximize the flushing effect.

Whenever possible, air should be exhausted from a low level in rooms

\section{Unidirectional airflow (UDAF)}

Unidirectional airflow should be used where appropriate to provide product protection by supplying a clean air supply over the product, minimizing the ingress of contaminants from surrounding areas.

Where appropriate the unidirectional airflow should also provide protection to the operator from contamination by the product.

Sampling should be carried out in the same environmental condition that is required for the further processing of the product. In some cases, sampling cubicles located in warehouses are used. These cubicles should normally provide a unidirectional airflow screen to ensure that clean air is flowing over the container when it is opened. (Note: Unidirectional flow normally provides a Class A (ISO Class 5, operational, $0.5 \square \mathrm{m}$ ) environment, but for a sampling cubicle this degree of protection may not be required).

In a weighing booth situation, the aim should be to provide dust containment.

A dispensary or weighing weigh booth should be provided with unidirectional airflow for product and operator protection. 
The source of the dust and the position in which the operator normally stands should be determined before deciding on the direction of unidirectional flow (FIG:4).

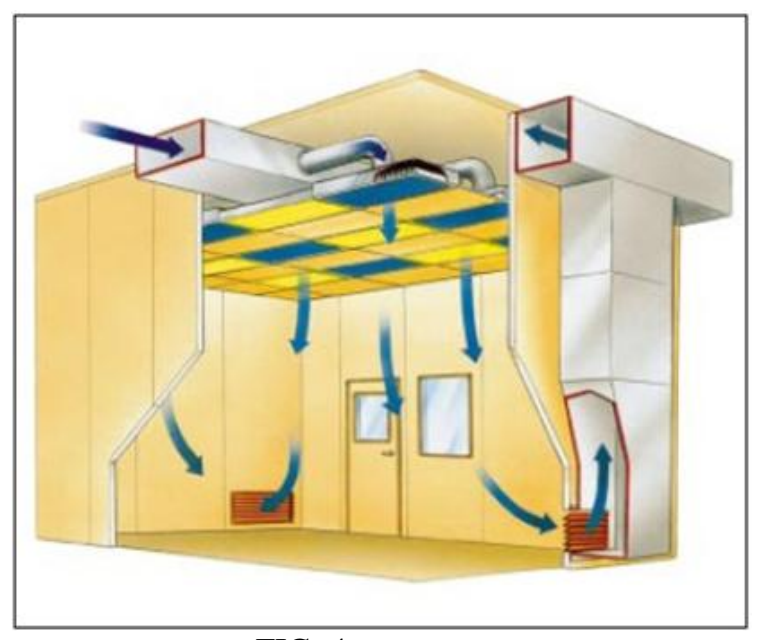

\section{Infiltration}

FIG: 4

Air infiltration of unfiltered air into a pharmaceutical plant should not be the source of contamination.

Manufacturing facilities should be maintained at a positive pressure relative to the outside, in order to limit the ingress of contaminants. Where facilities are to be maintained at negative pressures relative to ambient, in order to prevent the escape of harmful actives to the outside (such as penicillin and hormones), then special precautions should be taken.

The location of the negative pressure facility should be carefully considered with reference to the areas surrounding it, and particular attention given to ensuring that the building structure is well sealed.

Negative pressure zones should, as far as possible, be encapsulated by surrounding areas with clean air supplies, so that only clean air can infiltrate into the controlled zone.

\section{Cross-contamination}

Where different products are manufactured at the same time, in different areas/cubicles, in a multiproduct OSD manufacturing site, measures should be taken to ensure that dust cannot move from one cubicle to another.

Correct directional air movement and a pressure cascade system can assist in preventing crosscontamination. The pressure cascade should be such that the direction of air flow is from the clean corridor into the cubicles, resulting in dust containment.

The corridor should be maintained at a higher pressure than the cubicles, and the cubicles at a higher pressure than atmospheric pressure.

Containment can normally be achieved by the displacement concept (low pressure differential, high airflow), or the pressure differential concept (high pressure differential, low airflow), or physical barrier concept.

The choice of pressure cascade regime and choice of airflow direction should be considered in relation to the product and processing method used).

Highly potent products should be manufactured under a pressure cascade regime that is negative to atmospheric pressure.

The pressure cascade for each facility should be individually assessed according to the product handled and level of protection required.

Building structure should be given special attention because of the pressure cascade design. Airtight ceilings and walls, close fitting doors and sealed light fittings should be in place.

\section{System operating ranges}

For a pharmaceutical facility some of the typical HVAC system parameters that should be qualified may include:

$>$ temperature;

$>$ relative humidity;

$>$ supply air quantities for all diffusers;

$>$ return air or exhaust air quantities;

$>$ room air change rates; 
$>$ room pressures (pressure differentials);

$>$ room airflow patterns;

$>$ unidirectional flow velocities;

$>$ containment system velocities

$>$ HEPA filter penetration tests;

$>$ room particle counts;

$>$ room clean-up rates;

$>$ microbiological air and surface counts where appropriate;

$>$ operation of dedusting;

$>$ warning/alarm systems where applicable.

\section{Professional Experiences}

As visiting at Radiant Pharma of Bangladesh following design and room data sheet has been given:
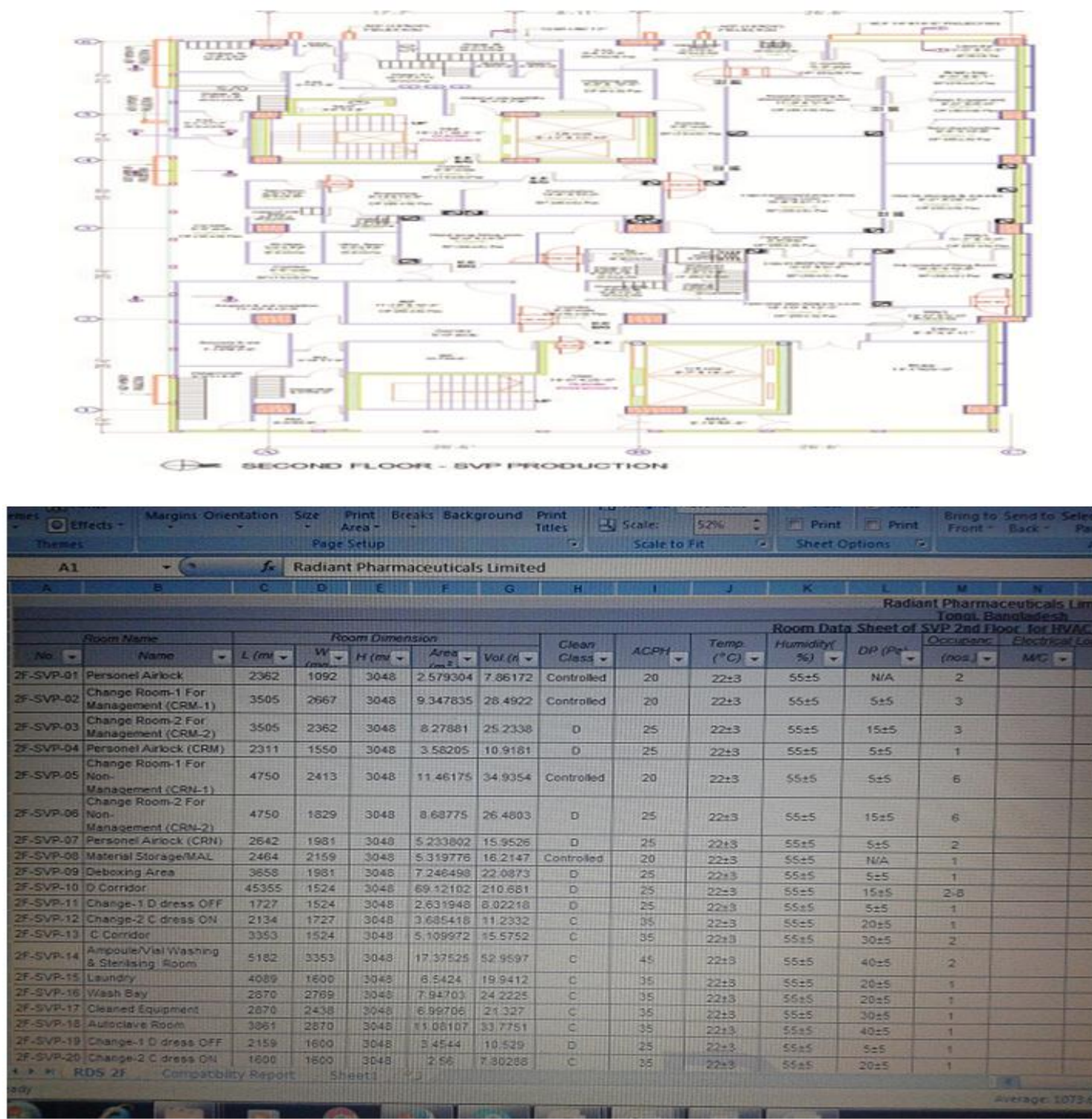

FIG: 5

\section{Limitation:}

\section{Conclusion}

1. It cannot be possible to use warning/alarm system everywhere.

2. The pressure cascade for each facility should be individually assessed therefore time cannot be consumed

Though it has limitations but modern era is very dependable on these. Specially in pharmaceutical sector these are very effective. Hence, all kinds safety for human is possible by this HVAC system. So, this system is absolutely welcome for modern era. 